\title{
ASSIGNMENT OF ABO LOCUS TO 9q31.3 $\rightarrow$ qter BY STUDY OF A FAMILY IN WHICH AN INTRACHROMOSOMAL SHIFT INVOLVING CHROMOSOME 9 IS SEGREGATING
}

\author{
Kouji Narahara, Yukio Takahashi, Kiyoshi KıKKawa, \\ Yoshiharu WaKita, Shunsuke Kimura, and \\ Hiroshi Кiмото \\ Department of Pediatrics, Okayama University School of \\ Medicine, Okayama 700, Japan
}

\begin{abstract}
Summary A family in which an intrachromosomal shift, dir ins(9) (q22.1q31.3; 34.3 ), was segregating is described. A meiotic crossing over in the noninsertional loop of the carrier mother appeared to have resulted in the proband with a recombinant chromosome 9 duplicating the interstitial segment $9 \mathrm{q} 22.1 \rightarrow \mathrm{q} 31.3$. The study of $\mathrm{ABO}$ and $\mathrm{AK}_{1}$ phenotypes in the family showed that the proband was also a recombinant for the ABO locus. These results allowed us to assign the ABO locus to $9 \mathrm{q} 31.3$ $\rightarrow$ qter on the cytogenetic basis.
\end{abstract}

\section{INTRODUCTION}

The determination of the locus for ABO blood group (ABO) on 9q34 has been founded on the linkage studies in families (Robson et al., 1977; Cook et al., 1978). The lack of the deletion mapping for $\mathrm{ABO}$ is due to the unavailability of a patient with monosomy for the distal portion of the long arm of chromosome 9 with an informative genotype of ABO. In Human Gene Mapping 8 (1985), cytogenetic evidence for the assignment of $\mathrm{ABO}$ to $9 \mathrm{q} 34$ has been presented by Allderdice et al. (1985), who have analyzed $\mathrm{ABO}, \mathrm{AK}_{1}$ (adenylate kinase 1) and ORM (orosomucoid) in kindreds in whom a specific rearrangement (an inverted insertional translocation of $9 \mathrm{q} 34.1 \rightarrow \mathrm{q} 34.3$ into $9 \mathrm{q} 22.1$ ) was segregating. Their data suggest that $\mathrm{ABO}$ maps to $9 \mathrm{q} 22.1 \rightarrow \mathrm{q} 34.1, \mathrm{AK}_{1}$ to $9 \mathrm{q} 34.1 \rightarrow \mathrm{q} 34.3$ and $O R M$ $9 \mathrm{q} 34.3 \rightarrow$ qter. Similarly, we saw a family in which the proband was found to have a recombinant chromosome deriving from a maternal intrachromosomal shift, dir ins(9)(q22.1q31.3;q34.3). The segregation study of $A B O$ and $A K_{1}$ in the family indicated that $\mathrm{ABO}$ can be assigned to $9 \mathrm{q} 31.3 \rightarrow$ qter.

Received February 19, 1986; revised version received April 28, 1986; Accepted May 19, 1986 


\section{MATERIALS AND METHODS}

Case report. The proband, a 5 year 5 month-old girl, was referred to us for evaluation of short stature. Family history (Fig. 1) showed early trimester spontaneous abortions in the mother (II-3) and maternal grandmother (I-2), and low birth weight and short stature in her cousin (III-2). The parents and sibling were healthy. The patient was born after uneventful 40 weeks' gestation, when the mother was 22 years old and the father 28 . Her birth weight was $2,430 \mathrm{~g}$, and her length $46.0 \mathrm{~cm}$. At two months of age, her dislocation of the right hip joint was conservatively treated. Although her psychomotor development was normal, the physical growth was markedly retarded. At the age of 5 years and 5 months, she measured only $85.5 \mathrm{~cm}$, with the body weight of $10.2 \mathrm{~kg}$ and the head circumference of $44.3 \mathrm{~cm}$ (all figures far less than the $3 \mathrm{rd}$ percentile). Her short stature was proportionate. She was found to have hypertelorism with epicanthic folds, but otherwise appeared normal. Her IQ was estimated to be 92 (Tanaka-Binet Intelligence Scores). The bone age ( 2 years and 2 months) was much delayed for the chronological age, but endocrinological studies yielded normal results. Dermatoglyphic study showed digital patterns consisting of U.U.W.W.U on the left hand and U.U.W.W.U on the right, a low total finger ridge count (82), and bilateral

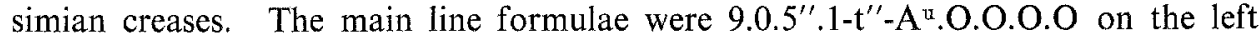
palm and 9.7.5"1-t" $-\mathrm{A}^{\mathrm{u}}$.O.O.O. $\mathrm{L}^{\mathrm{d}}$ on the right.

Cytogenetic study. Chromosome analyses were performed on cultured peripheral blood lymphocytes from the patient, sibling, parents and maternal grandparents. Cells in prophase and prometaphase were collected according to the method of Ikeuchi and Sasaki (1979). Chromosome preparations were processed by G-, Q-, R- and C-banding techniques.

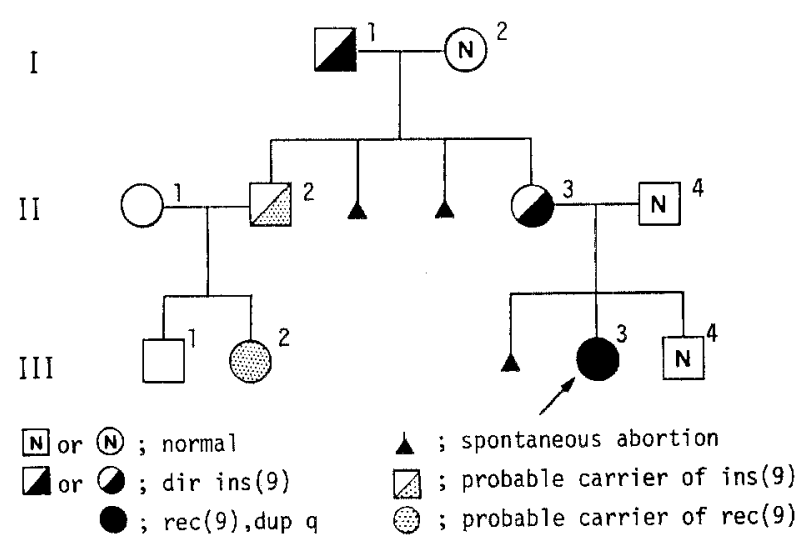

Fig. 1. The family pedigree. 
Gene marker studies. Blood group typing of freshly collected erythrocytes was carried out using the standard agglutination test. Erythrocyte activities of galactose-1-phosphate uridyl transferase (GALT) and adenylate kinase (AK) were assayed by the method of Beutler (1975). Starch gel electrophoresis was used to determine an AK phenotype, as described by Harris and Hopkinson (1976).

\section{RESULTS}

\section{Cytogenetic study}

The karyotype of the patient showed an extra amount of chromosome material on the terminal portion of the long arm of a chromosome 9 (Fig. 2, a). The mother was found to have an intrachromosomal shift of the interstitial segment of the long arm of chromosome 9 into its own distal end (Fig. 2, b). From the G- and Rbanding patterns, the most pertinent interpretation of the rearrangement is a direct insertional translocation of the segment $9 \mathrm{q} 22.1 \rightarrow \mathrm{q} 31.3$ into the long arm at band 9q34.3. The abnormal chromosome of the patient seemed to be a recombinant resulting from a crossing over during meiosis in the mother. The karyotype of the patient was therefore $46, X X, \operatorname{rec}(9), \operatorname{dup}(q 22.1 \rightarrow q 31.3)$, dir ins(9)(pter $\rightarrow \mathrm{q} 22.1:: \mathrm{q} 31.3$

G

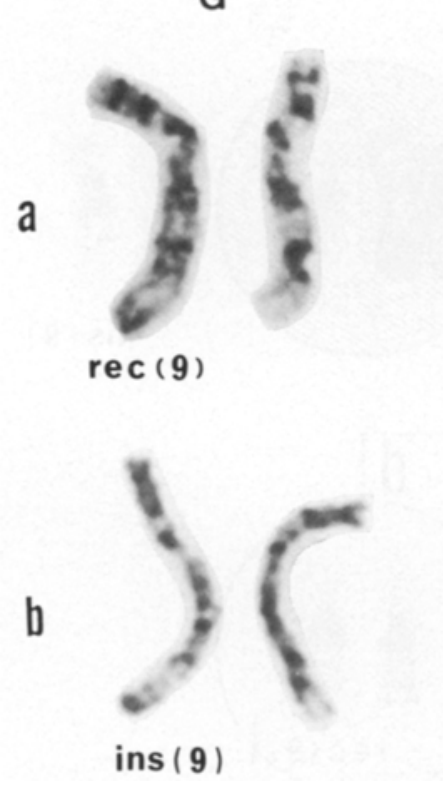

$\mathbf{R}$

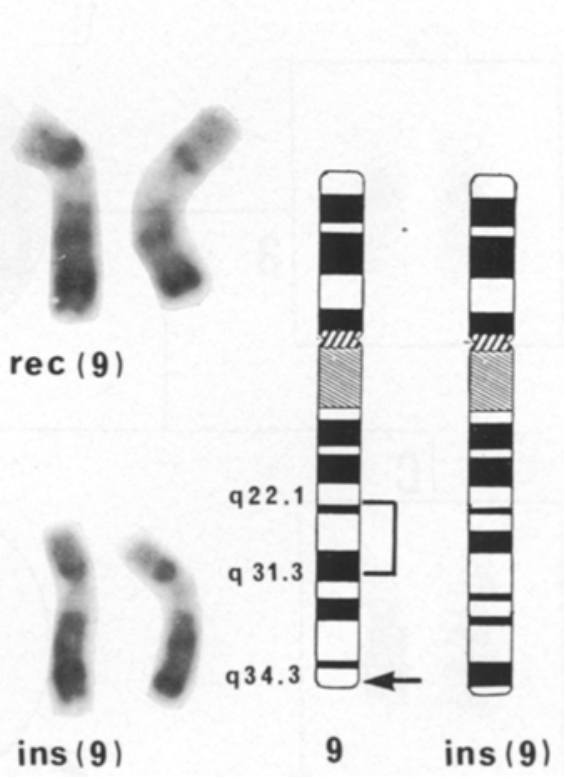

Fig. 2. The partial G- and R-banding karyotypes of the patient (a) and the mother (b). As depicted in the diagram of the inserted chromosome 9 of the mother [ins(9)], the interstitial segment $9 \mathrm{q} 22.1 \rightarrow \mathrm{q} 31.3$ (bracket) was transposed into $9 \mathrm{q} 34.3$ (arrow). 
$\rightarrow \mathrm{q} 34.3:: \mathrm{q} 22.1 \rightarrow \mathrm{q} 31.3: \mathrm{q} 34.3 \rightarrow \mathrm{qter}) \mathrm{mat}$. The father and sibling had normal chromosomes.

The sequential Q- and C-banding analysis showed that the inserted chromosome 9 of the mother contained a partially inverted C-heterochromatic region of $9 q(9 q h)$, while the normal homologue had a common type of 9qh heteromorphism (Fig. 3). The father and sibling had a common type of $9 \mathrm{qh}$ heteromorphism in both chromosomes 9. The $9 \mathrm{qh}$ heteromorphism in the recombinant chromosome 9 of the patient was identical to that in the normal chromosome 9 of the mother.

As shown in Fig. 1, the maternal grandfather (I-1) was also found to possess the insertional translocation. Although chromosome study was unavailable for the uncle (II-1) and the cousin (III-2), the phenotypic similarity between the patient and the cousin suggested that the uncle was a probable carrier of the insertional translocation and the cousin the recombinant chromosome.

\section{Gene marker studies}

Results of blood group typing in the available family members were given in Table 1. The affirmative probability of parentage on the patient was calculated to be 0.921 . The family was informative for the segregation of ABO blood group. The father was homozygous (genotype OO), while the mother heterozygous (genotype AO). Since the maternal grandfather (a carrier of the shift) had a phenotype

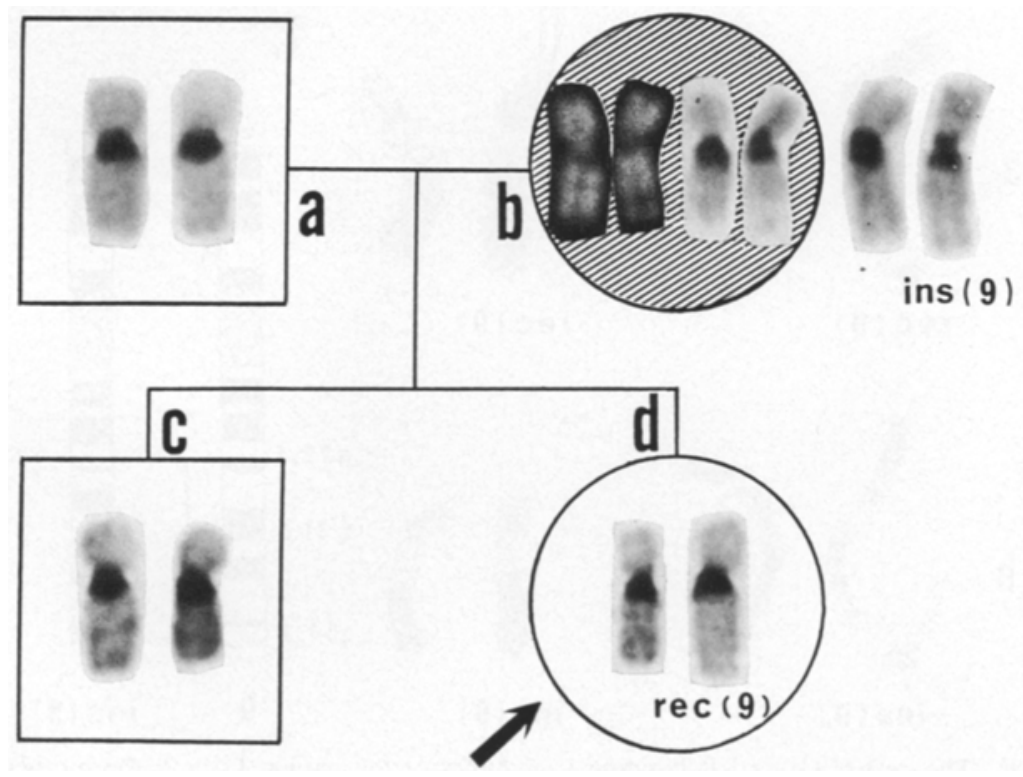

Fig. 3. The partial C-banding karyotypes of the father (a), mother (b), sibling (c) and patient (d). Sequentially stained chromosomes 9 of the mother were shown in the hatched circle, and another pair of chromosomes 9 right to this circle. 


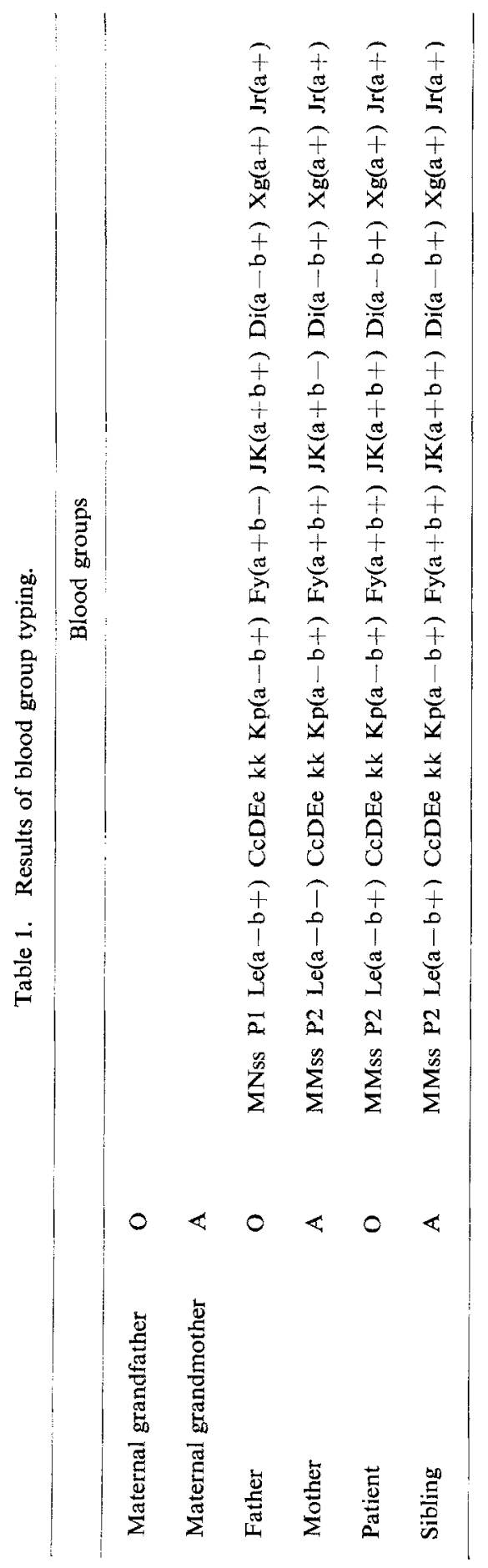

Vol. 31, No. 3, 1986 
$\mathrm{O}$ and the grandmother $\mathrm{A}$, the inserted chromosome 9 and the normal homologue of the mother must contain gene $O$ and $A$, respectively. The blood type of the two children (the patient $O$ and the sibling $A$ ) suggested that the patient was a recombinant as regards the ABO locus, too. It was reported that the uncle had a phenotype $\mathrm{O}$.

The GALT and AK activities of erythrocytes from the patient were within the normal ranges (GALT: $20.2 \mathrm{U} / \mathrm{g} \mathrm{Hb}$, normal $20.1 \pm 2.4 \mathrm{U} / \mathrm{g} \mathrm{Hb}, \mathrm{AK}: 258.2 \mathrm{U} / \mathrm{g}$ $\mathrm{Hb}$, normal $232.6 \pm 42.1 \mathrm{U} / \mathrm{g} \mathrm{Hb}$ ). Electrophoresis of hemolysates for $\mathrm{AK}$ isozyme showed that the patient and parents had an $\mathrm{AK}_{1}$ phenotype 1.

\section{DISCUSSION}

The present study has provided another cytogenetic evidence for the physical assignment of the ABO locus to the distal 9q. As depicted in Fig. 4, the chromosomes 9 of the carrier mother are predisposed to the meiotic crossing over in the noninsertional loop, which is much longer than the insertional loop, and consequently appears to result in the recombinant chromosome seen in the patient. The preservation of the same $9 \mathrm{qh}$ heteromorphism in the recombinant chromosome of the patient as in the normal chromosome 9 of the mother suggests that there is no (or less likely an even number of) crossing over in the segment from the $9 \mathrm{qh}$ to the origin of the insertional loop (q22.1). The mean chiasma frequency on the long arm of chromosome 9 is reported to be 1.28 (Laurie et al., 1982). This, together with the observation that the patient was a recombinant for the ABO locus, leads

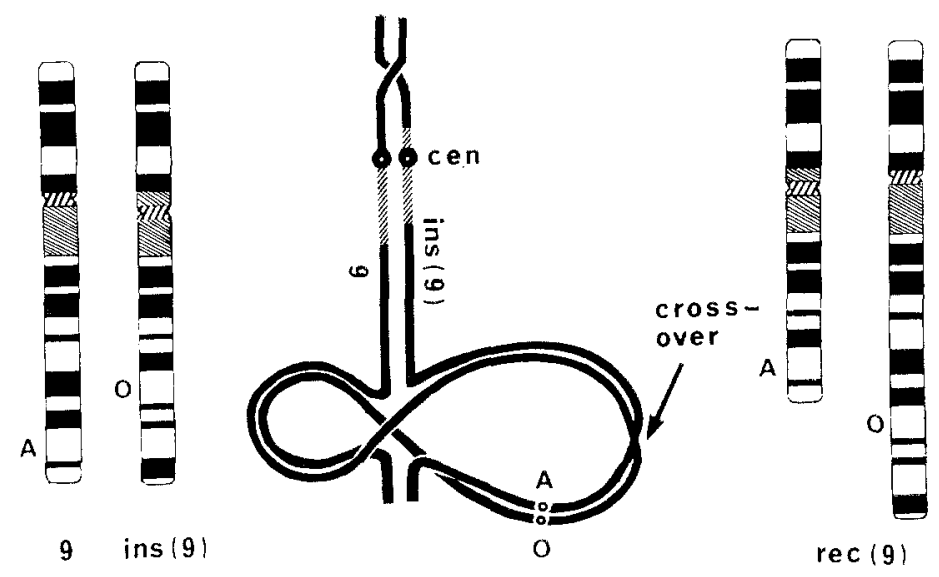

Fig. 4. Schematic representation of the meiotic pairing and crossing over in the mother which produce the cytogenetic and gene marker's phenomena seen in the patient. The most reasonable explanation is that a single crossing over has occurred proximally to the ABO locus within the noninsertional loop. 
us to assume that the $\mathrm{ABO}$ locus must be distal to the site of the meiotic crossing over.

The assignment of the ABO locus to the distal 9q was first established by the linkage study of $\mathrm{AK}_{1}$ locus (Robson et al., 1977), which was mapped to $9 \mathrm{q} 34$ by studies of somatic cell hybridization (Westerveld et al., 1976) and gene dosage effects (Ferguson-Smith and Aitken, 1978). Cook et ai. (1978), studying the segregation of $\mathrm{ABO}$ and $\mathrm{AK}$ in families with various abnormalities of chromosome 9, demonstrated that these loci have to be near the end of the long arm of chromosome 9. Two other loci, ALDA (aminolevylinate dehydratase) and ORM, have been found to be linked with $\mathrm{ABO}$ or $\mathrm{AK}_{1}$ (Eiberg et al., 1981; Eiberg et al., 1983), and on the basis of the lod scores the gene order, $\mathrm{ABO}-\mathrm{AK}_{1}-\mathrm{ALDA}-\mathrm{ORM}$ is suggested. The proposition of Allderdice et al. (1985) that $\mathrm{ABO}$ maps to $9 \mathrm{q} 22.1 \rightarrow \mathrm{q} 34.1, \mathrm{AK}_{1}$ to $9 \mathrm{q} 34.1 \rightarrow \mathrm{q} 34.3$ and ORM to $9 \mathrm{q} 34.3 \rightarrow \mathrm{qter}$ is in good agreement with this gene order. In consideration of the proposition of Allderdice et al. (1985), we would like to conclude on the cytogenetic basis that the ABO locus lies within the region $9 q 31.3 \rightarrow q 34.1$ This physical assignment is not contradictory to the result of the genetic assignment that the distance between $A B O$ and ORM is 27 centimorgans (cM) in males (Eiberg et al., 1983), whose genetic length of the whole $9 \mathrm{q}$ is presumed to be $65 \mathrm{cM}$ (Norton et al., 1982).

Finally, individuals with a recombinant resulting from an intrachromosomal shift will show 'pure' deletion or duplication of the inserted segment. As far as we are aware, the present case is the first instance of pure trisomy for 9q22.1 $\rightarrow$ q31.3. We believe that triplication of this chromosome segment produces few phenotypic abnormalities.

\section{REFERENCES}

Allderdice, P.W., Kaita, H., Lewis, M., McAlpine, P.J., Wong, P., Anderson, J., and Gilblett, E.R. 1985. Segregation of marker loci in families with an inherited paracentric inversion of chromosome 9: evidence that ABO is proximal to AK 1 and ORM. Cytogenet. Cell Genet. 40: 161.

Beutler, E. 1975. Red Cell Metabolism: A Manual of Biochemical Methods, 2nd Ed., Grune Stratton, New York, pp. 83-85, 91-94.

Cook, P.J.L., Robson, E.B., Buckton, K.E., Slaughter, C.A., Gray J.E., Blank, C.E., James, F.E., Ridler, M.A.C., Insley, J., and Hulten, M. 1978. Segregation of ABO, AK 1 and ACONS in families with abnormalities of chromosome 9. Ann. Hum. Genet. 41: 365-376.

Eiberg, H., Mohr, J., and Nielsen, L.S. 1981. Linkage of orosomucoid (ORM) to ABO and AK 1. Cytogenet. Cell Genet. 32: 272.

Eiberg, H., Mohr, J., and Nielsen, L.S. 1983. Delta-aminolevulinate dehydrase; synteny with ABO-AK 1-ORM (and assignment to chromosome 9). Clin. Genet. 23: 150-154.

Ferguson-Smith, M.A. and Aitken, D.A. 1978. Gene dosage: further information on the regional position of the $\mathrm{ABO}: \mathrm{Np}: \mathrm{AK} 1$ linkage group on chromosome 9. Cytogenet. Cell Genet. 22: 449-451

Harris, H. and Hopkinson, D.A. 1976. Handbook of Enzyme Electrophoresis in Human Genetics, North Holland Publishing Company, Amsterdam. 
Ikeuchi, T. and Sasaki, M. 1979. Accumulation of early mitotic cells in ethidium bromide-treated human lymphocyte cultures. Proc. Jpn. Acad. 55: 15-18.

Laurie, D.A., Hulten, M.A., and Jones, G.H. 1982. Chiasma frequency and distribution in a sample of human males: chromosomes 1, 2, and 9. Cytogenet. Cell Genet. 31: 153-166.

Morton, N.E., Lindsten, J., Iselius, L., and Yee, S. 1982. Data and theory for a revised chiasma map of man. Hum. Genet. 62: 266-270.

Robson, E.B., Cook, P.J.L., and Buckton, K.E. 1977. Family studies with the chromosome 9 markers ABO, AK 1, ACON and 9qh. Ann. Hum. Genet, 41: 53-60.

Westerveld, A., Jongsma, A.P.M., Meera Khan, P., van Someren, H., and Bootsma, D. 1976. Assignment of the AK $1: \mathrm{Np}:$ ABO linkage group to chromosome 9. Proc. Natl. Acad. Sci. USA 73: 895-899. 